HIII) 


\section{Werke von Gerd W. Goede im Oldenbourg Verlag}

Bisher erschienene Werke:

Goede, Wirtschaftsenglisch-Lexikon, Englisch-Deutsch · Deutsch-Englisch, 4. Auflage

(3 Bände im Schuber)

Goede, Lexikon des Internationalen Handels,

Englisch-Deutsch $\cdot$ Deutsch-Englisch

Goede, Marketing-Lexikon,

Englisch-Deutsch $\cdot$ Deutsch-Englisch 


\title{
Wirtschaftsenglisch Lexikon
}

Englisch-Deutsch

$$
\text { A-K }
$$

\author{
Von \\ Gerd W. Goede
}

4., völlig überarbeitete und erweiterte Auflage

R.Oldenbourg Verlag München Wien 


\section{Die Deutsche Bibliothek - CIP-Einheitsaufnahme}

Goede, Gerd W.:

Wirtschaftsenglisch-Lexikon : englisch-deutsch, deutsch-englisch / von Gerd W. Goede. - München ; Wien : Oldenbourg

ISBN 3-486-27280-2

Englisch-Deutsch. - A - K. - 4, völlig überarb. und erw. Aufl. - 2003

Englisch-Deutsch. $-\mathrm{L}-\mathrm{Z}$. -4 , völlig überarb. und erw. Aufl. -2003

Deutsch-Englisch : A - Z. - 4., völlig überarb. und erw. Aufl. - 2003

(C) 2003 Oldenbourg Wissenschaftsverlag GmbH

Rosenheimer Straße 145, D-81671 München

Telefon: (089) 45051-0

www.oldenbourg-verlag.de

Das Werk einschließlich aller Abbildungen ist urheberrechtlich geschützt. Jede Verwertung außerhalb der Grenzen des Urheberrechtsgesetzes ist ohne Zustimmung des Verlages unzulässig und strafbar. Das gilt insbesondere für Vervielfältigungen, Übersetzungen, Mikroverfilmungen und die Einspeicherung und Bearbeitung in elektronischen Systemen.

Gedruckt auf säure- und chlorfreiem Papier

Gesamtherstellung: Druckhaus „,Thomas Müntzer“ GmbH, Bad Langensalza 
Meinen Eltern / To my parents:

Margarete Ch. H. Goede

Walter G. A. Goede 
Do your work with your whole heart

and you will succeed - there is so little competition.

Elbert Hubbard, $1856-1915$

American publisher and author 